\title{
A Rapid Detection Method for Bridges Based on Impact Coefficient of Standard Bumping
}

\author{
Xiaolan Liu $\mathbb{D}^{\mathrm{D}}{ }^{1}$ Xianmin Zhang, ${ }^{2,3}$ and Yadong Wang ${ }^{4}$ \\ ${ }^{1}$ Ph.D. Student, College of Civil Aviation, Nanjing University of Aeronautics and Astronautics, No. 29 Jiangjun Road, \\ Nanjing City, Jiangsu Province, 211100, China \\ ${ }^{2}$ Professor, College of Civil Aviation, Nanjing University of Aeronautics and Astronautics, No. 29 Jiangjun Road, Nanjing City, \\ Jiangsu Province, 211100, China \\ ${ }^{3}$ College of Airport Engineering, Civil Aviation University of China, No. 2898 Jinbei Road, Dongli District, Tianjin City, 300300, China \\ ${ }^{4}$ Assistant Engineer, CCCC-Airport Investigation and Design Institute Co., Ltd., No. 161 Qingjin Road, Guangzhou City, \\ Guangdong Province, 510230, China
}

Correspondence should be addressed to Xiaolan Liu; 1066323835@qq.com

Received 6 June 2018; Revised 17 August 2018; Accepted 12 September 2018; Published 30 September 2018

Academic Editor: Lukasz Pieczonka

Copyright (C) 2018 Xiaolan Liu et al. This is an open access article distributed under the Creative Commons Attribution License, which permits unrestricted use, distribution, and reproduction in any medium, provided the original work is properly cited.

\begin{abstract}
The evaluation method of load transfer efficiency using falling weight deflectometer is unworkable in remote mountain areas and transportation difficult region. Therefore, a novation method of load transfer efficiency evaluation is proposed using the index of amplitude ratio. Finite element method is applied to study the influence of dowel bar parameters (diameter, length, spacing, and elastic modulus) and pavement structures parameters (thickness and modulus) on load transfer efficiency, frequency, and the ratio of amplitude. Results of finite element model show that the effects of dowel bar and pavement structure parameters on load transfer efficiency and the ratio of amplitude are similar. The load transfer efficiency, frequency, and the ratio of amplitude enhance with the increase of dowel bar diameter, length, and elastic modulus and the decrease of dowel bar spacing. The subgrade modulus has more significant influence on the load transfer efficiency, frequency, and the ratio of amplitude than other pavement parameters. Polynomial function method is utilized to established load transfer mode between deflection-based load transfer efficiency and the ratio of amplitude. The feasibility and reliability of new method is verified by static and dynamic load test. All results are helpful for the development of highway engineering and airport engineering.
\end{abstract}

\section{Introduction}

Structural and functional defects, damage, and failure appear inordinately in bridges through the combined action of a moving vehicle and the environment. Thus, regular tests are necessary to guarantee the security and serviceability of bridges. Static load testing, as a main detection method of bridges, is backed by well-developed theory and technology; however, it is costly and time consuming and causes serious traffic congestion, which is hazardous when the traffic flow cannot be easily suspended to carry out load tests [1-3]. Thereby, dynamic load testing is now of considerable interest to bridge engineers, because it is faster and more efficient than its static equivalent $[4,5]$. Moreover, it causes less traffic congestion by using moving vehicles as a continuous source of energy for the bridge [6, 7]. González et al. (2010) [8], He et al. (2014) [9], and Podworna and Klasztorny (2014) [10] found that the results of dynamic load testing are inevitably influenced by deck conditions, vehicle, and stiffness and form of bridges. Park et al. (2005) [11] researched the function of roughness on dynamic load testing through full-scale field tests. Ding et al. (2009) [12] explored the relationship between deck roughness and dynamic load coefficient through evolutionary spectral method. Liu et al. (2015) [13] and Jiang et al. (2011) [14] emphasized the influence of speed and deck roughness on dynamic load testing. Huang et al. (2011) [15] showed that fundamental frequency and impact coefficient have close correlation in dynamic load testing. Kim et al. (2007) [16] reported that bump height is a key factor of impact coefficient in dynamic load testing. Qi et al. [17] (2013) 
studied the effect factor of width-span ratio on dynamic load testing. Wang and Jiang (2016) [18] analyzed the effect factors of dynamic load testing, and they were able to obtain bridge health situation using the smallest vibration impact coefficient.

However, existing dynamic load testing methods were not able to achieve the reliability and accuracy requirements of static load testing. Therefore, the main objective of our study is to test and analyze bridges displacement and strain with moving vehicle to obtain loading efficiency. As the influence of deck roughness on bridge dynamic tests must be considered, although difficult to quantitatively describe, a new method of standard bumping is proposed to desensitize the effect of deck roughness on vehicle-bridge interaction. Moreover, the software of MATLAB was used to solve coupled vibration equation caused by vehicle-bridge interaction, and the factors of vehicle-bridge coupled vibration were explored further based on dynamic load testing and standard bumping testing. The results of numerical simulation and experiments demonstrate that standard bumping tests effectively decreased the influence of deck roughness and avoid the difficulty of quantitative deck roughness, which in turn leads to the realization of rapid and accurate detection of loadcarrying capacity of bridges.

\section{Theoretical Analysis}

2.1. Load Carrying Capacity Assessment of Bridges. Static load testing is the most direct and effective method to assess the load-carrying capacity of bridges, in which static loads are placed on bridges in the most unfavorable loading way to measure the actual stress, strain, and displacement of bridges [19]. The ratio between static load testing and theory calculating values is defined as the calibration coefficient of bridges to assess bridge load-carrying capacity, in which

$$
\eta=\frac{S_{e}}{S_{s}}
$$

Here, $\eta$ is the calibration coefficient of bridges, $S_{\mathrm{e}}$ states the measuring values in static load testing, and $S_{\mathrm{s}}$ represents the theory calculating values. When $\eta$ is more than 1 , bridges are seriously damaged and the load-carrying capacity of bridges would be insufficient. Otherwise, bridges are safe and have enough load-carrying capacity. The smaller the value of $\eta$ is, the safer the bridge structure would be.

As compared with static load testing, dynamic load testing not only surpasses disadvantages, but it also establishes the relationship of detection results in static and dynamic load testing: [20]

$$
1+\mu=\frac{S_{d}}{S_{e}}
$$

where $1+\mu$ is the impact coefficient of bridges and $S_{\mathrm{d}}$ represents the measuring values in dynamic load testing.

It is known that the key in dynamic load testing is to obtain suitable impact coefficients to calculate static stress, strain, and displacement of bridges. Nonetheless, existing dynamic load testing methods show difficulty in deciding vehicle load to satisfy complete bridge evaluation and loading

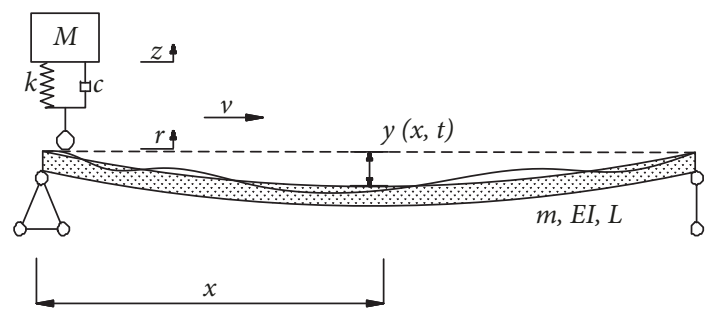

FIGURE 1: Vehicle-bridge interaction model.

efficiency such as that when $1+\mu$ is 1.5 , a 20 -T vehicle load in dynamic load testing would be equal to $30-\mathrm{T}$ vehicle load in static load testing.

Thus, we propose a standard bumping method in which a standard vehicle passes over bridges and bumps over a standard height wooden plank placed at the midspan position of the bridge; the bridge evaluation is completed by inserting the measured values of dynamic load testing into (2) and by taking the calculated static values from (2) into (1).

2.2. Vehicle-Bridge Interaction Model. In vehicle-bridge interaction model, vehicle loads and bridges are simplified as single-degree-of-freedom mass-spring system and onedimensional structure, respectively, in which time $(\mathrm{t})$ and distance along the bridge axis (x), instead of bridge width, are considered in vehicle-bridge interaction equation (Figure 1).

The factors affecting impact coefficient include vehicle speed, deck roughness, stiffness, and structural form of bridges. However, the effect of random deck roughness on impact coefficient of bridges is difficult to determine and test. Thus, vehicle-bridge coupling vibration partial differential equations, including the influence of deck roughness, are established based on D' Alembert's principle [21].

$$
\begin{aligned}
E I & \frac{\partial^{4} y}{\partial x^{4}}+m \frac{\partial^{2} y}{\partial t^{2}} \\
& =\left[M g+k(z-y-r)+c\left(z^{\prime}-y^{\prime}-y^{\prime} v-r^{\prime} v\right)\right] \\
& \cdot \delta(x-v t) \\
M & \frac{d^{2} z}{d t^{2}}+k(z-y-r)+c\left(z^{\prime}-y^{\prime}-y^{\prime} v-r^{\prime} v\right)=0
\end{aligned}
$$

Here, $m, E, I$, and $y$ represent the unit length quality $(\mathrm{kg} / \mathrm{m})$, elastic modulus $(\mathrm{Pa})$, bending inertia moments $\left(\mathrm{m}^{4}\right)$, and deflection functions $(\mathrm{m})$ of simply supported girder bridge, respectively. $M, z, k, c$, and $v$ represent vehicle mass $(\mathrm{kg})$, vehicle quality displacement relative to equilibrium position $(\mathrm{m})$, vehicle suspension spring stiffness $(\mathrm{N} / \mathrm{m})$, spring damp$\operatorname{ing}(N \bullet \mathrm{s} / \mathrm{m})$, and speed $(\mathrm{m} / \mathrm{s})$, respectively. Lastly, $r$ and $\delta$ are deck roughness (m) and Delta-Dirac function, respectively.

According to the principle of modal superposition

$$
\begin{aligned}
y & =\sum_{n=1}^{N} \varphi_{n(x)} q_{n(t)} \\
\varphi_{n(x)} & =\sin \frac{n \pi x}{L}
\end{aligned}
$$


TABLE 1: Deck roughness coefficient $G_{x\left(n^{\prime}\right)}$ of different levels.

\begin{tabular}{lccc}
\hline Level & $\mathrm{Gx}\left(\mathrm{n}^{\prime}\right)\left(10^{-6} \mathrm{~m}^{2}(\mathrm{~m}-1)-1\right)$ & Level & $\mathrm{Gx}\left(\mathrm{n}^{\prime}\right)\left(10^{-6} \mathrm{~m}^{2}(\mathrm{~m}-1)-1\right)$ \\
\hline A & 16 & $\mathrm{E}$ & 4,096 \\
B & 64 & $\mathrm{~F}$ & 16,384 \\
C & 256 & $\mathrm{G}$ & 65,536 \\
D & 1,024 & $\mathrm{H}$ & 262,144 \\
\hline
\end{tabular}

By taking (5) and (6) into (3) and (4), the orthogonality of vibration mode function would be

$$
\begin{aligned}
& \int_{0}^{L} m \varphi_{i(x)} \varphi_{j(x)} d x=0 \quad(i \neq j) \\
& \int_{0}^{L} E I \varphi_{i(x)}^{\prime \prime} \varphi_{j(x)}^{\prime \prime} d x=0 \quad(i \neq j)
\end{aligned}
$$

Boundary conditions: The beam displacement is zero at both ends, and the bending moment is equal to zero,

$$
y_{(0, t)}=\frac{\partial^{2} y_{(0, t)}}{\partial x^{2}}=y_{(L, t)}=\frac{\partial^{2} y_{(L, t)}}{\partial x^{2}}=0
$$

Equations (3) and (4) can be simplified into

$$
\begin{aligned}
& q_{i(t)}^{\prime \prime}+\omega_{i}^{2} q_{i(t)}=\frac{2}{m L}\left\{M g+k\left[z-\sum_{n=1}^{N} \sin \frac{n \pi x}{L} q_{n(t)}\right.\right. \\
& \left.-r_{(v t)}\right]+c\left[z^{\prime}-\sum_{n=1}^{N} \sin \frac{n \pi x}{L} q_{n(t)}^{\prime}-v \sum_{n=1}^{N} \frac{n \pi}{L}\right. \\
& \left.\left.\quad \times \sin \frac{n \pi x}{L} q_{n(t)}-r_{(v t)}^{\prime} v\right]\right\} \sin \frac{i \pi x}{L} \\
& M z^{\prime \prime}+k\left[z-\sum_{n=1}^{N} \sin \frac{n \pi x}{L} q_{n(t)}-r_{(v t)}\right]+c\left[z^{\prime}\right. \\
& -\sum_{n=1}^{N} \sin \frac{n \pi x}{L} q_{n(t)}^{\prime}-v \sum_{n=1}^{N} \frac{n \pi}{L} * \sin \frac{n \pi x}{L} q_{n(t)} \\
& \left.-r_{(v t)}^{\prime} v\right]=0
\end{aligned}
$$

Through the transformation, the complex problem solving of vehicle-bridge coupling vibration partial differential equations is converted into the problem solving of ordinary differential equations. Based on given initial conditions, which is $q_{i(0)}=0, q_{i(0)}{ }^{\prime}=0, z_{i(0)}=0$, and $z_{i(0)}{ }^{\prime}=0$, the fourth-order Runge-Kutta algorithm was used to solve the vehicle-bridge coupled vibration partial differential equations. Then, time series of $q_{i(t)}, q_{i(t)}{ }^{\prime}, z_{i(t)}$, and $z_{i(t)}{ }^{\prime}$ were obtained by MATLAB program, and the numerical solutions of (3) and (4) were determined. Finally, the solution of vehicle-bridge coupling systems was completed.

2.3. Deck Roughness. Deck roughness refers to the deviation of the ideal flat surface, and it is a zero mean and ergodic stationary Gauss random process, as described by roughness power spectral density: [22]

$$
G_{x(n)}=G_{x\left(n^{\prime}\right)}\left(\frac{n}{n^{\prime}}\right)^{-w}
$$

where, $n$ and $n^{\prime}$ represent spatial frequency and benchmark spatial frequency $(\mathrm{Hz} \cdot \mathrm{s} / \mathrm{m})$ and $G_{x(n)}$ and $G_{x\left(n^{\prime}\right)}$ state power spectral densities of $n$ and $n^{\prime}\left(10^{-6} \mathrm{~m}^{2}\left(\mathrm{~m}^{-1}\right)^{-1}\right)$, which are shown in Table 1. $w$ is frequency index, which descripts the trend of power spectral density that is usually 2 .

Due to isolation effects of vehicle suspension system, effective spatial frequency interval (i.e., $\left.\left(n_{u}, n_{l}\right)\right)$ has significant effects on vehicle vibration and is calculated using (13). Equation (12) is solved by trigonometric series method as shown in (14) and (15).

$$
f=v n
$$

Here, $f$ states vehicle vibration frequency, and $v$ represents vehicle speed.

$$
\begin{aligned}
r_{(x)} & =\sum_{k=1}^{N} A_{\left(n_{k}\right)} \cos \left(2 \pi n_{k} x+\phi_{k}\right) \\
A_{\left(n_{k}\right)} & =\sqrt{4 G_{x\left(n_{k}\right)} \Delta n}
\end{aligned}
$$

Here, $n_{k}$ is a discrete value in effective spatial frequency interval, and $n_{k}=n_{l}+(k-0.5) \times \Delta n . \Phi_{k}$ states random phase angle in uniform distribution of $0-2 \pi(\mathrm{rad}) . \mathrm{A}_{\left(n_{k}\right)}$ represents trigonometric function amplitude of $n_{k} . \Delta n$ is the resolution of effective spatial frequency, $\Delta n=\left(n_{u}-n_{l}\right) / \mathrm{N}$.

\section{Impact Coefficient Analysis of Standard Bumping}

3.1. Factors Influencing Impact Coefficient. The physical parameters of simply supported girder bridges are as follows: flexural rigidity is $E I=0.75 \mathrm{e} 10 \mathrm{~Pa} \bullet \mathrm{m}^{4}$, actual span is $L=13 \mathrm{~m}$, and unit mass is $m=14,700 \mathrm{~kg} / \mathrm{m}$. The physical parameters of vehicles are as follows: mass is $M=24,000 \mathrm{~kg}$; suspension spring rigidity is $k=2.8 \mathrm{e} 6 \mathrm{~N} / \mathrm{m}$; spring damp is $c=24,000$ $\mathrm{N} \bullet \mathrm{s} / \mathrm{m}$; and vehicle speed is $v=2 \mathrm{~m} / \mathrm{s}, v=4 \mathrm{~m} / \mathrm{s}, v=6 \mathrm{~m} / \mathrm{s}$, $v=8 \mathrm{~m} / \mathrm{s}, v=10 \mathrm{~m} / \mathrm{s}, v=20 \mathrm{~m} / \mathrm{s}, v=30 \mathrm{~m} / \mathrm{s}$, and $v=40 \mathrm{~m} / \mathrm{s}$. Midspan displacement is $1.43 \mathrm{~mm}$ with stationary vehicle load placed on the middle of bridges. The results of vehicle passing bridges at a uniform speed are shown in Figure 2 and Table 2.

Figure 2 and Table 2 show that impact coefficient moderately increased with vehicle speed growth and that growth 
TABLE 2: Maximum dynamic displacement and impact coefficient of midspan without deck roughness level.

\begin{tabular}{lcr}
\hline Vehicle speed $(\mathrm{m} / \mathrm{s})$ & Maximum dynamic displacement $(\mathrm{mm})$ & Impact coefficient \\
\hline 2 & 1.45 & 1.01 \\
4 & 1.46 & 1.02 \\
6 & 1.47 & 1.03 \\
8 & 1.49 & 1.04 \\
10 & 1.50 & 1.05 \\
20 & 1.55 & 1.08 \\
30 & 1.66 & 1.16 \\
40 & 1.69 & 1.18 \\
\hline
\end{tabular}

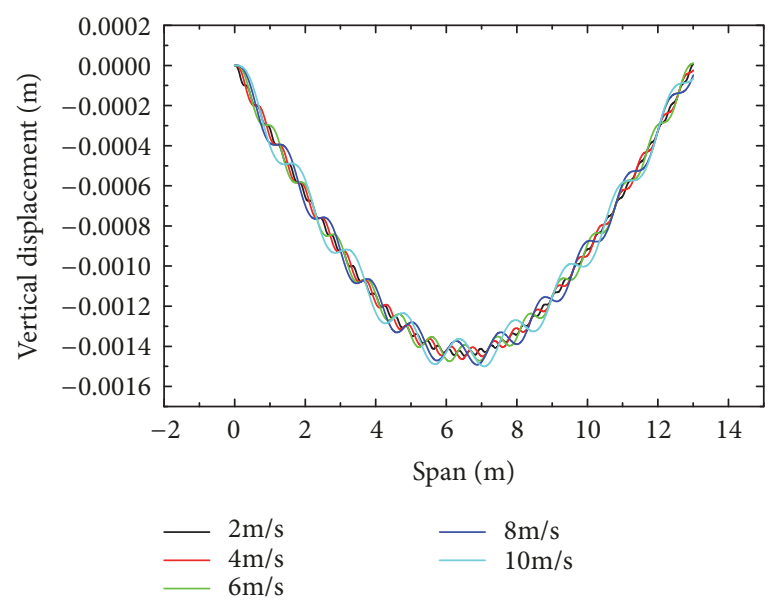

(a)

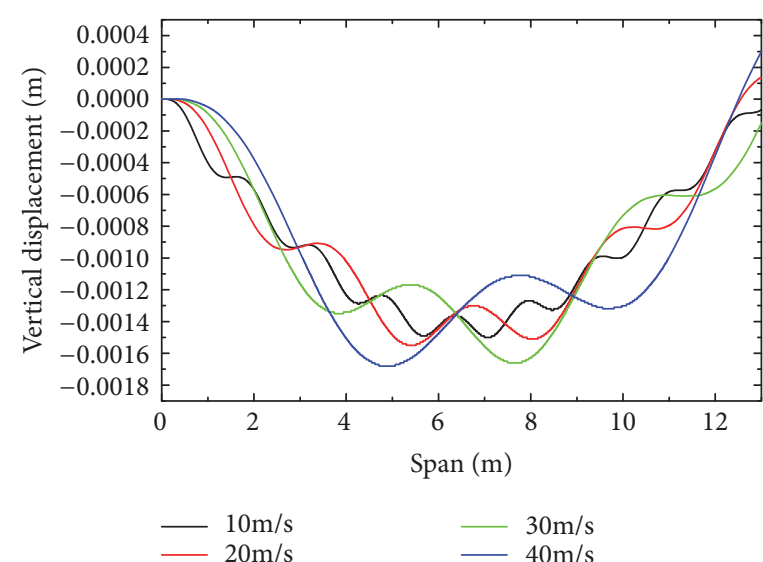

(b)

Figure 2: (a) Midspan displacement of simply supported girder bridges with 2-10m/s. (b) Midspan displacement of simply supported girder bridges with $10-40 \mathrm{~m} / \mathrm{s}$.

margin is minimal at speed of less than $10 \mathrm{~m} / \mathrm{s}$. When vehicle speed is less than $20 \mathrm{~m} / \mathrm{s}$, the impact coefficient variation of unit vehicle speed is $0.38 \%$, and when vehicle speed is between $20 \mathrm{~m} / \mathrm{s}$ and $30 \mathrm{~m} / \mathrm{s}$, the impact coefficient variation of unit vehicle speed is $0.80 \%$; furthermore, when vehicle speed is between $30 \mathrm{~m} / \mathrm{s}$ and $40 \mathrm{~m} / \mathrm{s}$, the impact coefficient variation of unit vehicle speed is $0.20 \%$. Therefore, the influence of vehicle speed on the impact coefficient is negligible when the speed is less than $10 \mathrm{~m} / \mathrm{s}$.

The physical parameters of simply supported girder bridges and vehicles are as aforementioned, and deck roughness levels are assigned as A, B, C, D, E, and F. The results of vehicle passing bridges at the speed of $4 \mathrm{~m} / \mathrm{s}$ are presented in Figure 3 and Table 3.

Figure 3 and Table 3 illustrate that deck roughness level significantly affected impact coefficient, which gradually increased with deck roughness levels ranging from $\mathrm{A}$ to $\mathrm{F}$. Deck roughness levels A, B, C, and D are common in actual bridges, and impact coefficient moderately varies with deck roughness from $\mathrm{A}$ to $\mathrm{D}$.

Equations (3) and (4) state that both vehicle speed and deck roughness influence vehicle-bridge interaction. Vehicle speed is a quantitative value, whereas deck roughness is random and difficult to be accurately measured. Hence, statistical method is used to analyze the influence of deck roughness on

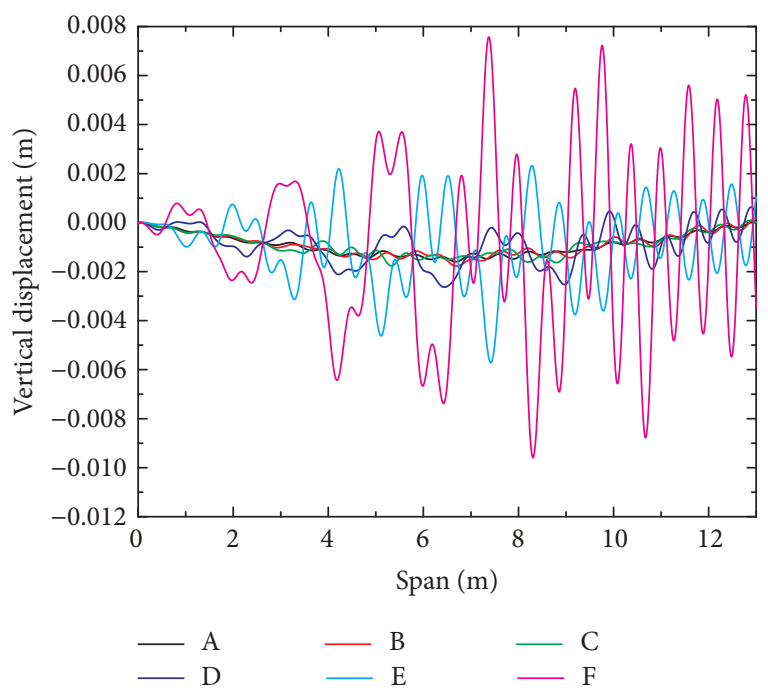

FIGURE 3: Midspan displacement of simply supported girder bridges with different deck roughness levels.

vehicle-bridge interaction. The physical parameters of simply supported girder bridges and vehicles are as aforementioned and vehicle speed is $v=2 \mathrm{~m} / \mathrm{s}, v=4 \mathrm{~m} / \mathrm{s}, v=6 \mathrm{~m} / \mathrm{s}, v=8 \mathrm{~m} / \mathrm{s}$, and 
TABLE 3: Maximum dynamic displacement and impact coefficient of midspan with different deck roughness levels.

\begin{tabular}{lcr}
\hline Deck roughness level & Maximum dynamic displacement $(\mathrm{mm})$ & Impact coefficient \\
\hline A & 1.53 & 1.07 \\
B & 1.73 & 1.21 \\
C & 2.03 & 1.42 \\
D & 3.32 & 2.32 \\
E & 6.06 & 4.23 \\
F & 9.59 & 6.71 \\
\hline
\end{tabular}

TABLE 4: Impact coefficients with different deck roughness levels (without standard bumping).

\begin{tabular}{lcccccccccc}
\hline $\begin{array}{l}\text { Vehicle speed } \\
(\mathrm{m} / \mathrm{s})\end{array}$ & $\begin{array}{c}\text { Absolute } \\
\text { smooth }\end{array}$ & \multicolumn{2}{c}{$\begin{array}{c}\text { Deck roughness } \\
\text { level of A }\end{array}$} & \multicolumn{2}{c}{$\begin{array}{c}\text { Deck roughness } \\
\text { level of B }\end{array}$} & \multicolumn{2}{c}{$\begin{array}{c}\text { Deck roughness } \\
\text { level of C }\end{array}$} & \multicolumn{2}{c}{$\begin{array}{c}\text { Deck roughness } \\
\text { level of D }\end{array}$} \\
& & Mean & Variance & Mean & Variance & Mean & Variance & Mean & Variance \\
\hline 2 & 1.01 & 1.05 & 0.0005 & 1.09 & 0.0013 & 1.21 & 0.0069 & 1.43 & 0.0245 \\
4 & 1.02 & 1.09 & 0.0015 & 1.18 & 0.0054 & 1.42 & 0.0246 & 1.95 & 0.1012 \\
6 & 1.03 & 1.09 & 0.0021 & 1.20 & 0.0061 & 1.46 & 0.0312 & 1.94 & 0.1047 \\
8 & 1.04 & 1.10 & 0.0027 & 1.19 & 0.0053 & 1.41 & 0.0263 & 1.92 & 0.0936 \\
10 & 1.05 & 1.10 & 0.0033 & 1.18 & 0.0111 & 1.43 & 0.0472 & 1.85 & 0.1349 \\
\hline
\end{tabular}

TABLE 5: Physical parameters and fundamental frequency of bridges.

\begin{tabular}{lccccc}
\hline Code & Section form & $E I\left(\mathrm{pa} \cdot \mathrm{m}^{4}\right)$ & $m(\mathrm{~kg} / \mathrm{m})$ & $l(\mathrm{~m})$ & 19.0 \\
\hline 1 & hollow slab & $1.84 \mathrm{E}+10$ & 14,000 & $1 \mathrm{~Hz})$ \\
2 & hollow slab & $2.78 \mathrm{E}+10$ & 17000 & 17.4 & 6.99 \\
3 & hollow slab & $1.11 \mathrm{E}+10$ & 13,000 & 20.3 & 8.59 \\
4 & T beam & $1.49 \mathrm{E}+10$ & 9,000 & 13.0 & 4.90 \\
5 & T beam & $1.42 \mathrm{E}+10$ & 8,000 & 6.8 & 16.3 \\
6 & T beam & $1.20 \mathrm{E}+10$ & 8,000 & 10.3 & 7.24 \\
7 & T beam & $7.99 \mathrm{E}+09$ & 7,000 & 15.82 \\
\hline
\end{tabular}

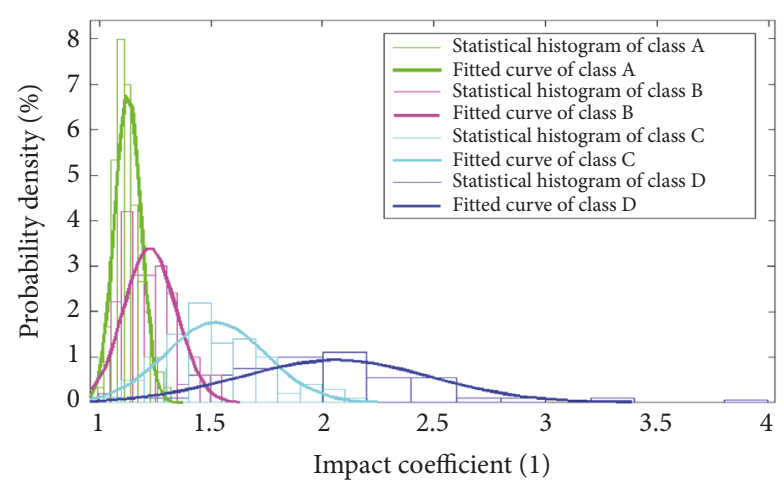

FIGURE 4: Probability density curve of impact coefficient at the speed of $10 \mathrm{~m} / \mathrm{s}$ without standard bumping.

$v=10 \mathrm{~m} / \mathrm{s}$. One-hundred deck roughness samples of deck roughness levels from $\mathrm{A}$ to $\mathrm{D}$ were randomly generated to calculate the impact coefficient of the midspan position. The results of vehicle passing bridges at uniform speed are shown in Figure 4 and Table 4.

Figure 4 and Table 4 show that mean and variance of impact coefficient gradually increased with deck roughness levels ranging from A to D. Moreover, impact coefficient became more discrete as deck roughness level was reduced. Therefore, deck roughness has a significant and random effect on impact coefficient.

As fundamental frequency is a function of bending stiffness $(E I)$, span $(l)$, and mass of unit length $(m)$, the relationship between fundamental frequency and impact coefficient can reflect the dynamic characteristics of vehicle-bridge interaction vibration. Taking three hollow slab bridges and four T beam bridges (physical parameters of bridges shown in Table 5) as examples, the physical parameters of vehicles are as aforementioned and vehicle speed is $v=4 \mathrm{~m} / \mathrm{s}$. The results with absolute smooth deck are shown in Table 6 .

In Tables 5 and 6 , the maximum impact coefficient of seven bridges is equal to 1.015; low speed is beneficial in reducing the influence of deck roughness on impact coefficient with different section form, bending stiffness, span, and mass of unit length. Impact coefficients were reduced with the increase in fundamental frequency of the same section form bridges; however, the correlation of impact coefficient and fundamental frequency are not evident for different section form bridges. Thereby, it is necessary to analyze the variation of impact coefficient with different section form bridges. 
TABLE 6: Physical parameters and impact coefficient of bridges.

\begin{tabular}{lcccc}
\hline Code & $f(\mathrm{~Hz})$ & Dynamic displacement $(\mathrm{mm})$ & Static displacement $(\mathrm{mm})$ & Impact coefficient \\
\hline 1 & 4.99 & 1.856 & 1.827 & 1.016 \\
2 & 6.63 & 0.941 & 0.929 & 1.013 \\
3 & 8.59 & 0.983 & 0.970 & 1.013 \\
4 & 4.90 & 2.789 & 2.751 & 1.014 \\
5 & 6.61 & 1.969 & 1.946 & 1.012 \\
6 & 7.24 & 1.789 & 1.768 & 1.012 \\
7 & 15.82 & 0.675 & 0.670 & 1.007 \\
\hline
\end{tabular}

TABLE 7: Impact coefficients with different deck roughness levels (with $5 \mathrm{~cm}$ bumping height).

\begin{tabular}{lcccccccccc}
\hline $\begin{array}{l}\text { Vehicle speed } \\
(\mathrm{m} / \mathrm{s})\end{array}$ & $\begin{array}{c}\text { Absolute } \\
\text { smooth }\end{array}$ & \multicolumn{2}{c}{$\begin{array}{c}\text { Deck roughness } \\
\text { level of A }\end{array}$} & \multicolumn{2}{c}{ Deck roughness } & \multicolumn{2}{c}{ Deck roughness } & \multicolumn{2}{c}{ Deck roughness } \\
level of B & \multicolumn{2}{c}{ level of D } & \multicolumn{2}{c}{ level of } \\
& & Mean & Variance & Mean & Variance & Mean & Variance & Mean & Variance \\
\hline 2 & 2.32 & 2.33 & 0.0011 & 2.32 & 0.0040 & 2.33 & 0.0240 & 2.38 & 0.0575 \\
4 & 2.33 & 2.33 & 0.0046 & 2.37 & 0.0157 & 2.32 & 0.0569 & 2.51 & 0.1779 \\
6 & 2.32 & 2.32 & 0.0049 & 2.33 & 0.0188 & 2.35 & 0.0969 & 2.66 & 0.2658 \\
8 & 2.26 & 2.26 & 0.0056 & 2.26 & 0.0220 & 2.35 & 0.0883 & 2.54 & 0.2211 \\
10 & 2.26 & 2.27 & 0.0051 & 2.28 & 0.0171 & 2.31 & 0.820 & 2.59 & 0.2101 \\
\hline
\end{tabular}

TABLE 8: Impact coefficients with different deck roughness levels (with $15 \mathrm{~cm}$ bumping height).

\begin{tabular}{lcccccccccc}
\hline $\begin{array}{l}\text { Vehicle speed } \\
(\mathrm{m} / \mathrm{s})\end{array}$ & $\begin{array}{c}\text { Absolute } \\
\text { smooth }\end{array}$ & \multicolumn{2}{c}{$\begin{array}{c}\text { Deck roughness } \\
\text { level of A }\end{array}$} & \multicolumn{2}{c}{$\begin{array}{c}\text { Deck roughness } \\
\text { level of B }\end{array}$} & \multicolumn{2}{c}{$\begin{array}{c}\text { Deck roughness } \\
\text { level of C }\end{array}$} & \multicolumn{2}{c}{$\begin{array}{c}\text { Deck roughness } \\
\text { level of D }\end{array}$} \\
& Mean & Variance & Mean & Variance & Mean & Variance & Mean & Variance \\
\hline 2 & 3.29 & 3.30 & 0.0011 & 3.30 & 0.0045 & 3.29 & 0.0159 & 3.30 & 0.0566 \\
4 & 3.31 & 3.31 & 0.0053 & 3.32 & 0.0209 & 3.32 & 0.0679 & 3.35 & 0.1932 \\
6 & 3.29 & 3.29 & 0.0053 & 3.28 & 0.0197 & 3.31 & 0.0632 & 3.46 & 0.3103 \\
8 & 3.22 & 3.22 & 0.0075 & 3.21 & 0.0186 & 3.21 & 0.1130 & 3.43 & 0.2943 \\
10 & 3.22 & 3.23 & 0.0042 & 3.20 & 0.0222 & 3.26 & 0.0928 & 3.37 & 0.2464 \\
\hline
\end{tabular}

3.2. Validation of Impact Coefficient Based on Standard Bumping. Approximate closed-form solutions were determined for the vehicle and bridge based on the following practical assumptions: (1) the vehicle remains in contact with the bridge at all times, as it is being driven and during bumping; (2) the effect of the wooden plank on deck roughness is negligible; (3) the spring-mass system executes vertical free fall with a certain initial velocity after leaving the wooden plank; and (4) the gravitational potential energy of mass is completely converted into kinetic energy in the process of bumping, with no loss of energy. The standard bump model is shown in Figure 5. As external force applied to a simply supported bridge directly determines its displacement, velocity, and acceleration with respect to the equilibrium position, the movement of mass in spring-mass system is the focus of analysis. Taking the equilibrium position of spring-mass system in its initial state as the origin of the coordinate system and the under orientation as the positive direction, the velocity and displacement of the mass after bumping were determined as $z_{(i+1)}^{\prime}=z_{(i)}^{\prime}+\sqrt{2 \times 9.8 \times h}$ and $z(i+1)=z(i)$, respectively, where $h$ is the bumping height and $z^{\prime}(i)$ and

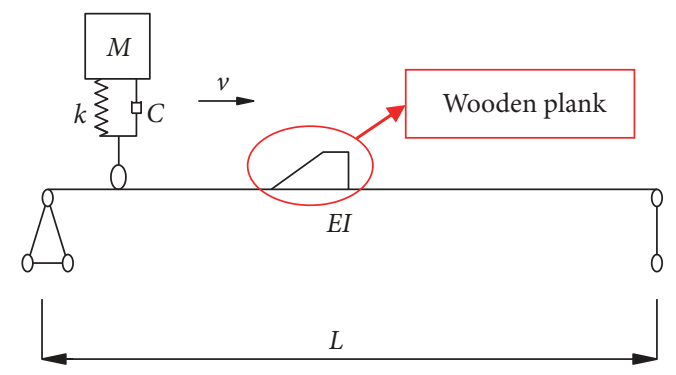

FIgURE 5: Standard bumping model.

$z(i)$ are the initial velocity and displacement of mass before bumping, respectively.

The physical parameters of simply supported girder bridges and vehicles are as aforementioned. The deck roughness levels are A, B, C, and D; vehicle speed is $v=2 \mathrm{~m} / \mathrm{s}$, $v=4 \mathrm{~m} / \mathrm{s}, v=6 \mathrm{~m} / \mathrm{s}, v=8 \mathrm{~m} / \mathrm{s}$, and $v=10 \mathrm{~m} / \mathrm{s}$, and bumping height is $5 \mathrm{~cm}, 10 \mathrm{~cm}$, and $15 \mathrm{~cm}$. The results of $5 \mathrm{~cm}$ bumping height are shown in Figure 6 and Table 7, and the results of $15 \mathrm{~cm}$ bumping height are shown in Table 8. 
TABle 9: Parameter of two test beams of simply supported girder bridge.

\begin{tabular}{lcccccc}
\hline Beam code & $\begin{array}{c}\text { Calculation } \\
\text { span }(\mathrm{mm})\end{array}$ & $\begin{array}{c}\text { Section } \\
\text { size }(\mathrm{mm})\end{array}$ & $\begin{array}{c}\text { Main rein- } \\
\text { forcement } \\
\text { diameter } \\
(\mathrm{mm})\end{array}$ & $\begin{array}{c}\text { Main rein- } \\
\text { forcement } \\
\text { quantity }\end{array}$ & $\begin{array}{c}\text { Stirrup } \\
\text { diameter } \\
(\mathrm{mm})\end{array}$ & $\begin{array}{c}\text { Stirrup } \\
\text { spacing } \\
(\mathrm{mm})\end{array}$ \\
\hline $1 \#$ & 3,500 & $300 \times 80$ & 12 & 3 & 6 & 120 \\
$2 \#$ & 3,500 & $600 \times 80$ & 12 & 5 & 6 & 130 \\
\hline
\end{tabular}

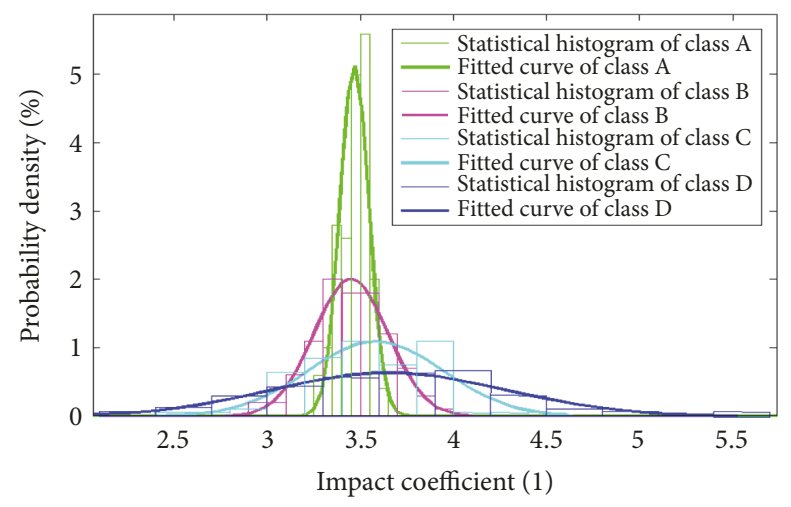

FIGURE 6: Probability density curve of impact coefficient at the speed of $10 \mathrm{~m} / \mathrm{s}$ with 5-cm bumping height.

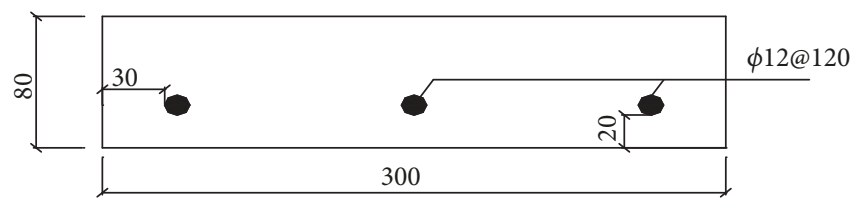

(a)

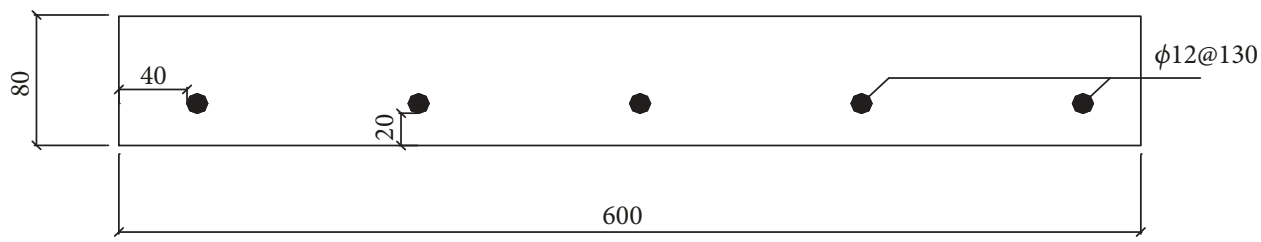

(b)

FiguRE 7: Section diagram of (a) 1\# test beam and (b) 2\# test beam.

Comparing Figures 4 and 6, the standard bumping test reduced the discreteness of impact coefficient, which can effectively reduce the influence of deck roughness on impact coefficient. Table 7 demonstrates that the relative variation ratio of impact coefficient, which is the ratio between the differences of maximum and minimum values and average values of impact coefficient, is $<4.78 \%$ at speeds of $\leq 10 \mathrm{~m} / \mathrm{s}$ and for bump height of $5 \mathrm{~cm}$ with relatively smooth decks (levels $\mathrm{A}$ and $\mathrm{B}$ ). However, the relative variation ratio of impact coefficient is $<3.68 \%$ at speeds $\leq 10 \mathrm{~m} / \mathrm{s}$ for bump height of $15 \mathrm{~cm}$ with rougher decks (levels $C$ and $D$ ) in Table 8. Thus, lower bump height can reduce the influence of deck roughness levels A and B on impact coefficient, whereas higher bump height can reduce the influence of deck roughness levels $\mathrm{C}$ and $\mathrm{D}$ on impact coefficient at the speed of less than $10 \mathrm{~m} / \mathrm{s}$.
To further verify the reliability and accuracy of standard bumping, two pieces of reinforced rectangular concrete section beams were made with C25 concrete (32.5 ordinary Portland cement, with density of $2,500 \mathrm{~kg} / \mathrm{m} 3$ and cement, sand, stone, and water quality ratio of 1:1.44:2.67:0.5), HRB335 steel, and HPB235 stirrup. As shown in Table 9 and Figures $7-$ 8 , the calculation spans of $1 \#$ and $2 \#$ simply supported girder bridges were both $3,300 \mathrm{~mm}$. The bending inertia moments of $1 \#$ and 2\# simply supported girder bridges were $4.32 \mathrm{e} 6 \mathrm{~mm}^{4}$ and $9.36 \mathrm{e}^{2} \mathrm{~mm}^{4}$, respectively. The elastic moduli of $1 \#$ and 2\# test beams were $2.52 \mathrm{e} 10 \mathrm{~Pa}$ and $1.89 \mathrm{e} 10 \mathrm{~Pa}$, respectively, with a $30-\mathrm{kg}$ concrete block and dial indicator applied in the bottom of midspan beam.

In Figure 9, the two test beams were tested by DHDAS5907 bridge modal apparatus and analysis system. Three speed sensors, which were placed at $1 / 4,1 / 2$, and $3 / 4$ span 


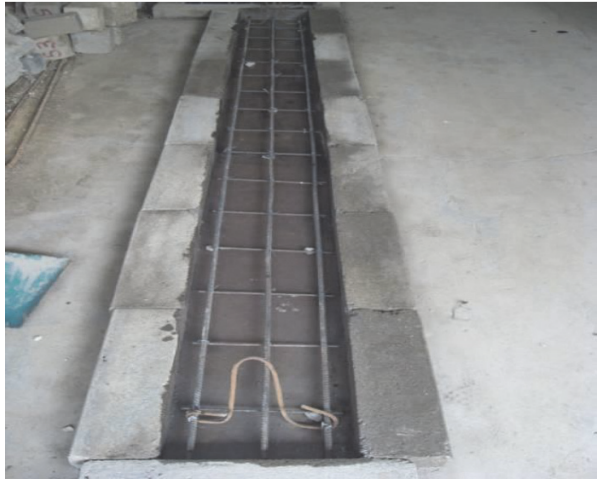

(a)

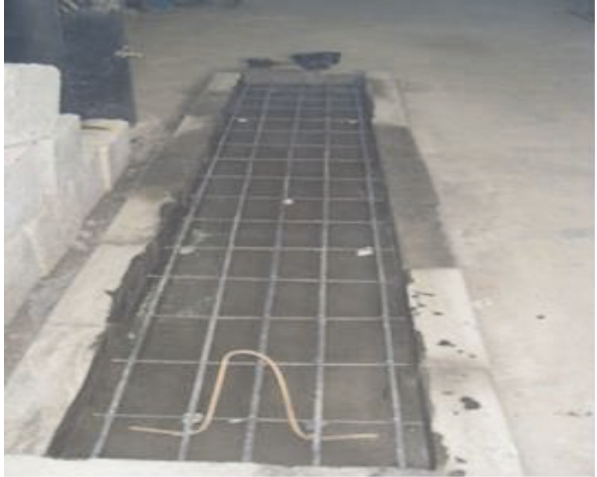

(b)

Figure 8: Preparation of (a) 1\# test beam and (b) 2\# test beam.

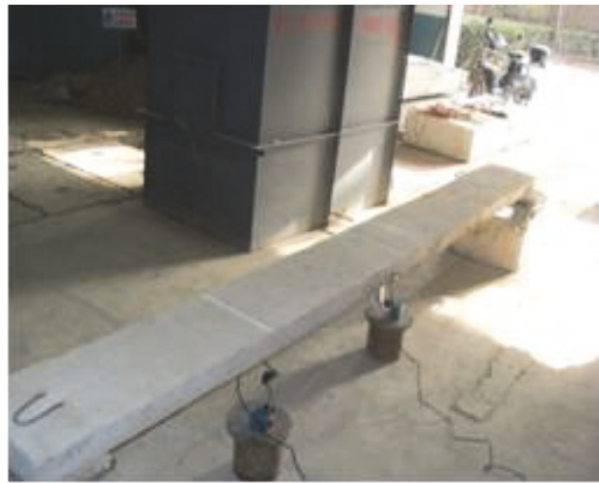

(a)

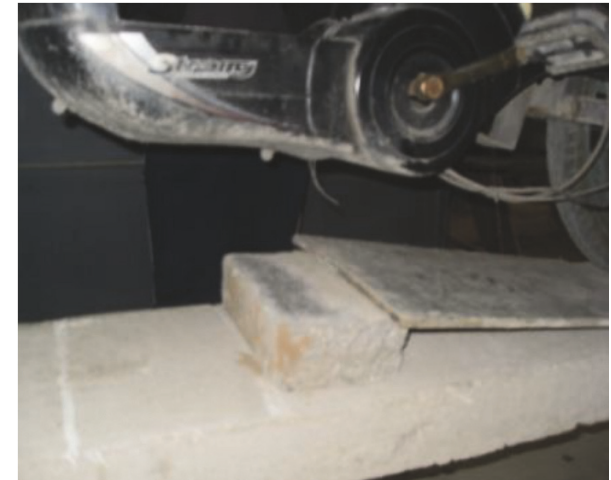

(b)

FIGURE 9: Laboratory test of standard bumping.

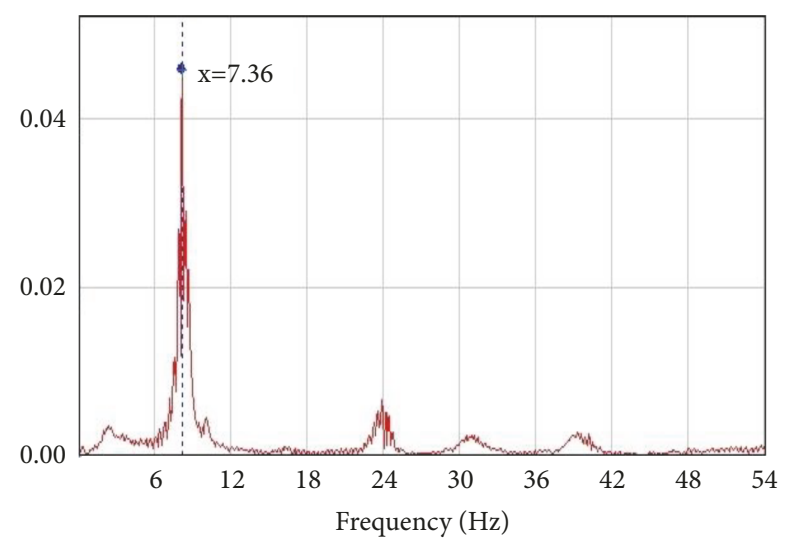

FIgURE 10: Measured frequency of 1 \# test beam.

of the test beams, were used to collect vibration speed signal for 6-8 mins. The fundamental frequencies of $1 \#$ and $2 \#$ test beams were determined as $7.36 \mathrm{H}_{\mathrm{Z}}$ (as shown in Figure 10) and $6.38 \mathrm{H}_{\mathrm{Z}}$ through spectrum analysis of vibration speed signal. The section sizes of $1 \#$ and $2 \#$ test beams were 0.080 $\times 0.3 \mathrm{~m}^{2}$ and $0.080 \times 0.6 \mathrm{~m}^{2}$, but the calculation spans of $1 \#$ and $2 \#$ test beams were both $3.3 \mathrm{~m}$. The elastic modulus of $1 \#$

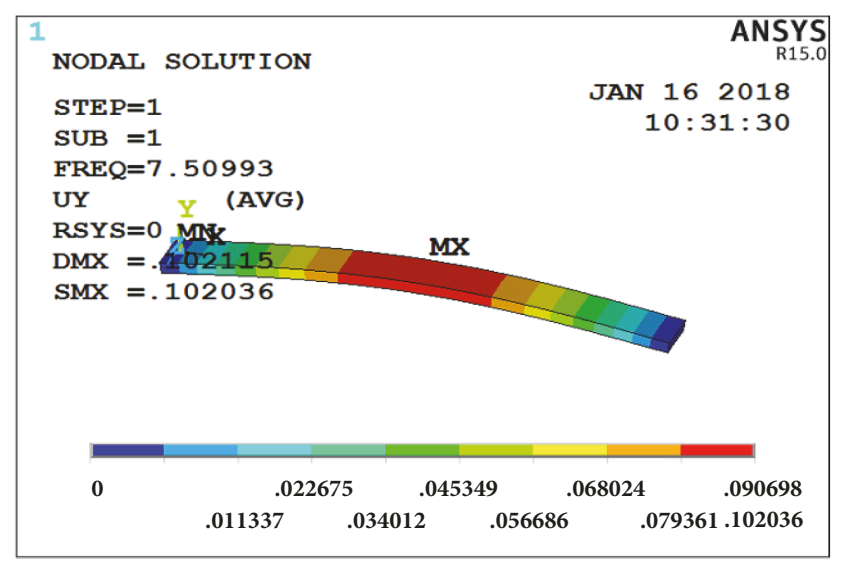

Figure 11: Calculated frequency of 1 \# test beam.

and 2 \# test beams were $2.52 \mathrm{e} 10 \mathrm{~Pa}$ and $1.89 \mathrm{el} 0 \mathrm{~Pa}$. The Poisson ratios of $1 \#$ and $2 \#$ test beams were both 0.2 . The fundamental frequencies of $1 \#$ and $2 \#$ test beams were $7.51 \mathrm{~Hz}$ (as shown in Figure 11) and $6.75 \mathrm{~Hz}$ as measured by Block Lanczos modal method with errors of $2.04 \%$ and $5.80 \%$, respectively, compared with measured frequency. Thus, the measurements verify that the two beam models are appropriate. 
TABle 10: Parameters of the test vehicle.

\begin{tabular}{lc}
\hline Measurement & Parameter \\
\hline Overall mass $(\mathrm{kg})$ & $\mathrm{M}_{0}=30,000$ \\
Mass of suspension above $(\mathrm{kg})$ & $\mathrm{m}_{\mathrm{cz}}=27,000$ \\
Mass of front axle $(\mathrm{kg})$ & $\mathrm{m}_{\mathrm{QZ}}=600$ \\
Mass of rear axle $(\mathrm{kg})$ & $\mathrm{m}_{\mathrm{HZ}}=2,400$ \\
Mass moment of inertia of the X axis $\left(\mathrm{kg} \cdot \mathrm{m}^{2}\right)$ & $\mathrm{J}_{\mathrm{x}}=1.0 \mathrm{e} 6$ \\
Mass moment of inertia of the $\mathrm{Y}$ axis $\left(\mathrm{kg} \cdot \mathrm{m}^{2}\right)$ & $\mathrm{J}_{\mathrm{y}}=3.6 \mathrm{e} 5$ \\
Suspension stiffness of front axle $(\mathrm{N} / \mathrm{m})$ & $\mathrm{K}_{\mathrm{xQZ}}=0.8 \mathrm{e} 6$ \\
Suspension stiffness of rear axle $(\mathrm{N} / \mathrm{m})$ & $\mathrm{K}_{\mathrm{xHZ}}=2.0 \mathrm{e} 6$ \\
Tire stiffness of front axle $(\mathrm{N} / \mathrm{m})$ & $\mathrm{K}_{\mathrm{LQZ}}=1.2 \mathrm{e} 6$ \\
Tire stiffness of rear axle $(\mathrm{N} / \mathrm{m})$ & $\mathrm{K}_{\mathrm{LHZ}}=4.8 \mathrm{e} 6$ \\
Suspension damping of front axle $(\mathrm{N} \cdot \mathrm{s} / \mathrm{m})$ & $\mathrm{C}_{\mathrm{xQZ}}=5.0 \mathrm{e} 3$ \\
Suspension damping of rear axle $(\mathrm{N} \cdot \mathrm{s} / \mathrm{m})$ & $\mathrm{C}_{\mathrm{xHZ}}=2.0 \mathrm{e} 4$ \\
Tire damping of front axle $(\mathrm{N} \cdot \mathrm{s} / \mathrm{m})$ & $\mathrm{C}_{\mathrm{LQZ}}=6.0 \mathrm{e} 3$ \\
Tire damping of rear axle $(\mathrm{N} \cdot \mathrm{s} / \mathrm{m})$ & $\mathrm{C}_{\mathrm{LHZ}}=2.4 \mathrm{e} 4$ \\
Distance between center of gravity and front axle $(\mathrm{m})$ & $\mathrm{L}_{\mathrm{QZ}}=3.6$ \\
Distance between center of gravity and rear axle $(\mathrm{m})$ & $\mathrm{L}_{\mathrm{HZ}}=0.9$ \\
Distance between center of gravity and left and right wheels & $\mathrm{L}_{\mathrm{y}}=0.9$ \\
\hline
\end{tabular}

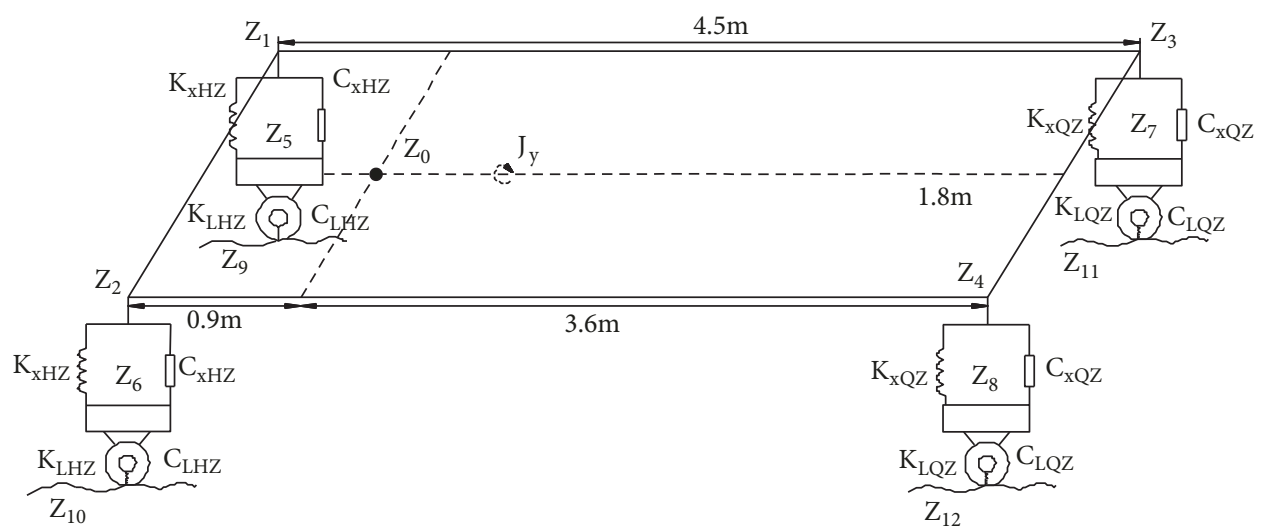

FIGURE 12: Vehicle model with seven DOFs.

The physical parameters of vehicles are as follows: front axle and rear axle mass were $10 \mathrm{~kg}$ and $45 \mathrm{~kg}$, respectively; distance between front axle and rear axle was $1.25 \mathrm{~m}$; spring stiffness and tire stiffness of front axle were $5 \mathrm{KN} / \mathrm{m}$ and 12 $\mathrm{KN} / \mathrm{m}$, respectively. Physical parameters of $1 \#$ test beam are as aforementioned. The static displacement was measured as $2.02 \mathrm{~mm}$ by static load testing. The dynamic displacement of measured value and calculated value were $4.94 \mathrm{~mm}$ and $4.77 \mathrm{~mm}$, respectively; and impact coefficients were 2.45 and 2.36 , with $3.67 \%$ error, thus proving that standard bumping method can exactly simulate vehicle-bridge interaction.

\section{Impact Coefficient Formula}

4.1. Vehicle Model. To make the results a more legitimate representative of actual bridge vibrations, ANSYS 10.0 simulation software was used to create vehicle-bridge interaction model in which the mass of suspension system was assigned to the front and rear axles of the vehicle in a mass ratio of 1:4 [23]. The testing vehicle was modeled as a three-dimensional mass-spring-damper system with seven degrees of freedom (DOFs), as shown in Table 10 and Figure 12. The tandems at the drive and rear axles of the test vehicle were lumped as single wheel for simplicity. Therefore, this model consisted of five rigid masses that represented the truck and its four wheels. The vehicle was assigned three DOFs, which correspond to the vertical displacement at the mass center, pitching rotation, and rolling rotation. Each wheel was modeled as a lumped mass with vertical displacement only. The vehicle was represented by beam elements (MPC184). The suspension and nonsuspension systems and the inertia moments of pitching and rolling rotations were represented by mass elements (Mass21). The spring and damper were represented by a spring-damper element (Combinel4).

4.2. Bridge Model. The reinforced concrete structure of the whole bridge was represented by Solid65 elements. Solid65 elements are also called reinforced concrete entity elements and they are used to simulate the unreinforced or 
TABLE 11: Parameters and analysis of simply supported hollow-slab bridges by static load testing.

\begin{tabular}{|c|c|c|c|c|c|c|}
\hline Bridge name & $\begin{array}{l}\text { Width } \\
\text { (m) }\end{array}$ & $\begin{array}{r}\text { Span } \\
(\mathrm{m})\end{array}$ & $\begin{array}{c}\text { Frequency } \\
\quad(\mathrm{Hz})\end{array}$ & $\begin{array}{c}\text { Front axle } \\
\text { displacement } \\
(\mathrm{mm})\end{array}$ & Rear axle displacement (mm) & Total displacement (mm) \\
\hline Luanhe Bridge & 10.0 & 19.0 & 5.11 & 0.32 & 1.83 & 2.15 \\
\hline Tatou Bridge & 12.0 & 17.4 & 6.13 & 0.15 & 0.93 & 1.08 \\
\hline Cichang Bridge & 12.4 & 13.0 & 6.77 & 0.15 & 1.43 & 1.58 \\
\hline Xiazhuang Bridge & 7.5 & 10.0 & 10.44 & 0.04 & 1.18 & 1.22 \\
\hline Xieliangkou Bridge & 10.1 & 13.0 & 8.26 & 0.11 & 0.97 & 1.08 \\
\hline
\end{tabular}

TABLE 12: Summary of impact coefficients of $15 \mathrm{~cm}$ bumping height.

\begin{tabular}{lccccc}
\hline Frequency & $\begin{array}{c}5.11 \mathrm{H}_{\mathrm{Z}} \\
\text { (Luanhe } \\
\text { Bridge) }\end{array}$ & $\begin{array}{c}6.13 \mathrm{H}_{\mathrm{Z}} \\
\text { (Tatou } \\
\text { Bridge) }\end{array}$ & $\begin{array}{c}6.77 \mathrm{H}_{\mathrm{Z}} \\
\text { (Cichang } \\
\text { Bridge) }\end{array}$ & $\begin{array}{c}8.26 \mathrm{H}_{\mathrm{Z}} \\
\text { (Xieliangkou } \\
\text { Bridge) }\end{array}$ & $\begin{array}{c}10.44 \mathrm{H}_{\mathrm{Z}} \\
\text { (Xiazhuang } \\
\text { Bridge) }\end{array}$ \\
\hline $2 \mathrm{~m} / \mathrm{s}$ & 3.54 & 3.28 & 3.01 & 2.87 & 2.76 \\
$4 \mathrm{~m} / \mathrm{s}$ & 3.55 & 3.41 & 3.05 & 2.81 & 2.78 \\
$6 \mathrm{~m} / \mathrm{s}$ & 3.57 & 3.29 & 3.09 & 2.81 & 2.78 \\
$8 \mathrm{~m} / \mathrm{s}$ & 3.60 & 3.33 & 3.06 & 2.77 & 2.68 \\
$10 \mathrm{~m} / \mathrm{s}$ & 3.57 & 3.31 & $2.53 \%$ & $3.73 \%$ & 2.67 \\
Change & $1.77 \%$ & $3.98 \%$ & & & $4.04 \%$ \\
\hline
\end{tabular}

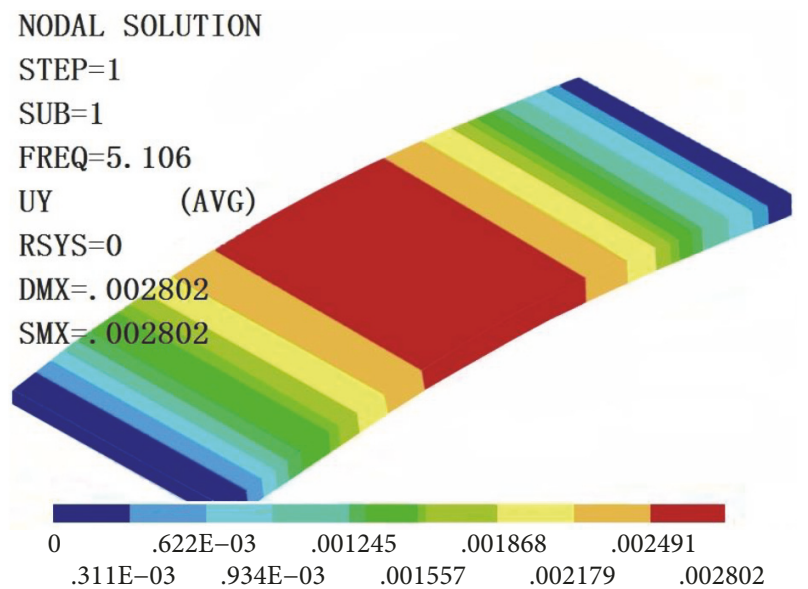

Figure 13: Fundamental frequency and mode shape of Luanhe Bridge.

reinforcement of the three-dimensional entity structure. Finally, the method of transient dynamic analysis was used to solve vehicle-bridge interaction model.

4.3. Impact Coefficient Formula. Finite element models of five simply supported hollow-slab bridges and five T-beam bridges were created in ANSYS 10.0 based on the design shown in Table 11. The fundamental frequencies of each bridge were determined through modal test (Figure 13). The displacements of the front and rear axles and the total structure were statically determined in a bumping test wherein a 30 -T test vehicle passed over a $15 \mathrm{~cm}$ wooden plank in the midspan of the test bridge (Table 12). Due to limitation in space, only the results of the simply supported hollow-slab bridge were presented in our study.

Tables 11 and 12 show that vehicle speeds that are less than $10 \mathrm{~m} / \mathrm{s}$ have minimal effect on impact coefficient. The relative variation ratio of the impact coefficient, or the ratio between the difference and mean of the maximum and minimum impact coefficients, was $<5.0 \%$ for each bridge and thus can be neglected. However, fundamental frequency of bridges has a significant influence on impact coefficient; and impact coefficients decline with the increase in fundamental frequency, as observed in the Ontario Highway Bridge Design Code (1982) but not in the General Code for Design of Highway Bridges and Culverts (JTG D60-2004). Thus, vehicle-bridge interaction vibration was able to affect impact coefficient but not JTG D60-2004.

The relationship between impact coefficient and fundamental frequency is better captured by a logarithmic function than a polynomial one. The fitting formula for the impact coefficient of a simply supported hollow-slab bridge is shown in (16). Impact coefficient fitting formulas of different bridge forms and bumping heights are listed in Table 13.

$$
1+\mu=-1.224 \ln (f)+5.497
$$

As double-vehicle loading is used in bridge testing to verify the lateral connection integrity and as single-vehicle loading concentrates the load distribution on a wide deck, five simply supported hollow-slab bridges were used to determine the impact coefficients for double-vehicle loading (Table 14). Parameters of vehicle and bridge are as aforementioned, and double vehicles passed over a bumping height of $15 \mathrm{~cm}$ side by side at the speed of $4 \mathrm{~m} / \mathrm{s}$ with a spacing of $1 \mathrm{~m}$.

Table 14 illustrates that, for all the simply supported hollow-slab bridges, the double-vehicle impact coefficient is 
TABLE 13: Impact coefficient formulas of different bridge forms and bumping heights.

\begin{tabular}{|c|c|c|c|c|}
\hline Simply supported bridge form & $\begin{array}{l}\text { Bumping } \\
\text { height } \\
(\mathrm{cm})\end{array}$ & Impact coefficient formula & Application scope (Hz) & $\begin{array}{c}\text { Correlation } \\
\text { coefficient } \\
\left(\mathrm{R}^{2}\right)\end{array}$ \\
\hline \multirow{3}{*}{ Hollow-slab } & 5 & $1+u=-0.616 \ln (f)+3.235$ & \multirow{3}{*}{$5 \leq f \leq 11$} & 0.9681 \\
\hline & 10 & $1+u=-0.894 \ln (f)+4.313$ & & 0.9721 \\
\hline & 15 & $1+u=-1.224 \ln (f)+5.497$ & & 0.9122 \\
\hline \multirow{3}{*}{ T-beam } & 5 & $1+u=-0.657 \ln (f)+3.379$ & \multirow{3}{*}{$5 \leq f \leq 16$} & 0.9661 \\
\hline & 10 & $1+u=-0.748 \ln (f)+4.092$ & & 0.9362 \\
\hline & 15 & $1+u=-0.616 \ln (f)+3.235$ & & 0.9681 \\
\hline
\end{tabular}

TABLE 14: Impact coefficients for single-vehicle and double-vehicle loading with $15 \mathrm{~cm}$ bumping height.

\begin{tabular}{lccc}
\hline Bridge & $\begin{array}{c}\text { Impact coefficient } \\
\text { (single vehicle) }\end{array}$ & $\begin{array}{c}\text { Impact coefficient } \\
\text { (double vehicle) }\end{array}$ & $\begin{array}{c}\text { Impact coefficient } \\
\text { relative variation } \\
\text { ratio }\end{array}$ \\
\hline Luanhe Bridge & 3.55 & 3.68 & $3.66 \%$ \\
Tatou Bridge & 3.41 & 3.57 & $4.69 \%$ \\
Cichang Bridge & 3.05 & 3.14 & $2.95 \%$ \\
Xiazhuang Bridge & 2.78 & 2.87 & $3.24 \%$ \\
Xieliangkou Bridge & 2.81 & 2.88 & $2.49 \%$ \\
\hline
\end{tabular}

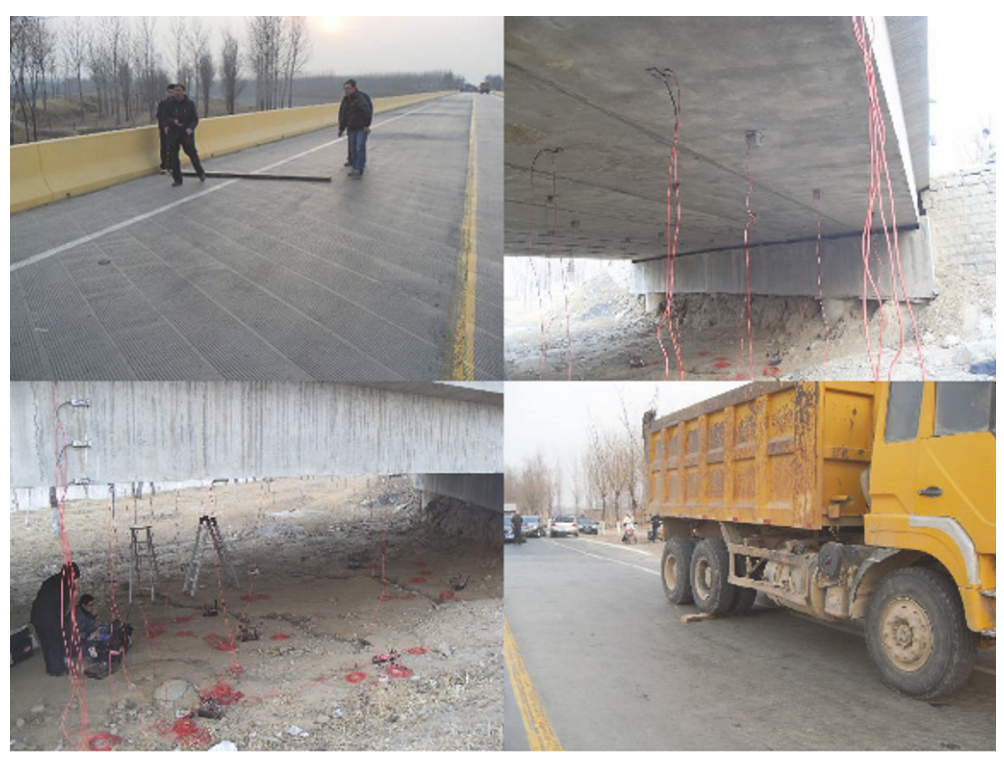

FIGURE 14: Overview of the tested bridge and tested vehicle.

only marginally greater than that of single-vehicle, with a variation of $<5.0 \%$. Therefore, the single-vehicle midspan impact coefficient formulas can also be used for doublevehicle cases.

\section{Engineering Application}

5.1. Test Bridge Description. The test bridge was built in 2000 in the town of Xiong in Baoding City, Hebei Province, China. It is a reinforced concrete, simply supported, and coreslabbed bridge with $4 \times 12.5 \mathrm{~m}$ spans, thus giving a total length of $50 \mathrm{~m}$ (Figure 14). The lateral structure of the bridge comprises nine hollow slabs that were $0.90 \times 1.20 \mathrm{~m}$ with fissure connections. The hinge joints and deck pavement were made from $\mathrm{C} 40$ and $\mathrm{C} 30$ waterproof concrete, respectively. The surface is hot-mix bituminous concrete. During testing, the deck slab, as viewed from the surface, was integral and was free from cracks, pits, spalling, subsidence, or any other defects. Likewise, as viewed from the bottom, the deck slab was free from cracks, seepage, hinged-joint exfoliation, etc. The fixed support was in uniform compression, and the spherical pedestal was free from defects. Therefore, the whole 
TABLE 15: Impact coefficients of static load testing and standard bumping testing.

\begin{tabular}{|c|c|c|c|c|c|}
\hline & Static load testing & Standard bumping testing & Measured impact coefficients & Calculated impact coefficients & Error \\
\hline Strain & $32.64 \mu \varepsilon$ & $74.86 \mu \varepsilon$ & 2.29 & 2.38 & $3.9 \%$ \\
\hline Displacement & $1.61 \mathrm{~mm}$ & $3.67 \mathrm{~mm}$ & 2.28 & 2.38 & $4.5 \%$ \\
\hline
\end{tabular}

TABLE 16: Calibration coefficient of static load testing and standard bumping testing.

\begin{tabular}{|c|c|c|c|c|}
\hline & Measured displacement $(\mathrm{mm})$ & Theory displacement (mm) & Calibration coefficient & Error \\
\hline Static load testing & 1.61 & 2.53 & 0.64 & \multirow{2}{*}{$4.7 \%$} \\
\hline Standard bumping testing & 3.67 & 2.53 & 0.61 & \\
\hline
\end{tabular}

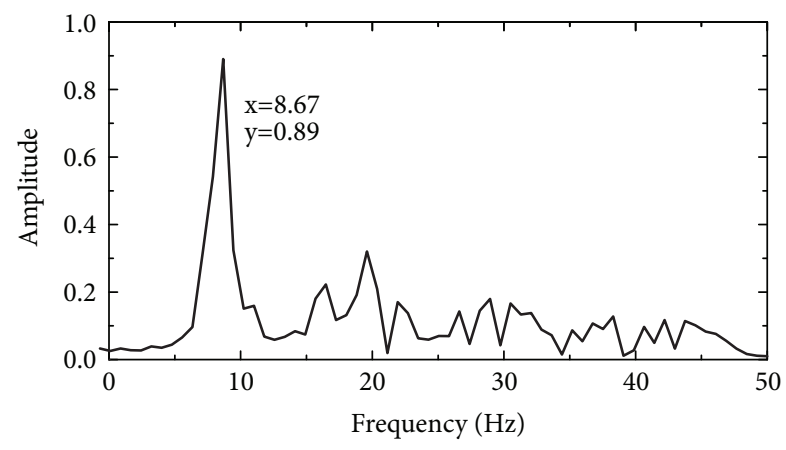

FIGURE 15: Fundamental frequency of the tested bridge.

bridge structure was in a satisfactory mechanical state with a deck roughness level of $\mathrm{B}$.

5.2. Instrumentation. The main testing instruments used were BDI Wireless Structural Testing System (STS-WiFi), sensors for acceleration displacement and strain, wireless data transmission nodes and base station, a Dynamic Habitual Displacement Analysis system (3817N), and a magnet support. Acceleration sensors provided information on the vibration of bridges, fundamental frequency, and mode shape obtained from modal analysis. Displacement sensors were applied to collect the signal of time-displacement relationship, and strain sensors were used to monitor the time-strain relationship.

5.3. Procedure and Analysis. Three methods of testing were used in our study. In modal testing, acceleration sensors placed at $1 / 6,1 / 3$, and $1 / 2$ span of the test bridge collected the vibration signals produced by moving vehicles for 360-480 seconds. The frequency and mode shape of the bridge were then determined by vibrational signal analysis. In static load testing, a 30-T two-axle vehicle was stationed at the midspan of the bridge for 30 seconds, perpendicular to the bridge axis, with displacement and strain sensors placed at the midspan. In standard bumping testing, the same vehicle passed over a $10-\mathrm{cm}$ tall wooden plank at the midspan of bridges, with a speed of $5 \mathrm{~m} / \mathrm{s}$.

Frequency spectrum analysis was applied to the acceleration-sensor vibration signal. The fundamental frequency of the test bridge is $8.67 \mathrm{~Hz}$ in Figure 15. Taking
$8.67 \mathrm{~Hz}$ into the formula of $1+u=-0.894 \ln (f)+4.313$, the calculated impact coefficient is 2.38 .

Figures 16 and 17 show static strain and displacement and dynamic strain and displacement, in which tensile strain is defined as the positive direction and compression as the negative direction. Impact coefficients were calculated by static and dynamic values and are listed in Table 15.

Table 15 shows that the errors of measured and calculated impact coefficients are less than $5 \%$ in both strain and displacement, which implicates the precision of impact coefficient formulas in this study.

Connecting theory displacement of $2.53 \mathrm{~mm}$ and static displacement of $1.61 \mathrm{~mm}$, the calculated calibration coefficient of bridges was 0.64 with static load testing. By taking displacement of standard bumping testing into (2) to solve for the static displacement of $1.54 \mathrm{~mm}$, the calculated calibration coefficient of bridges was 0.61 with standard bumping testing, as shown in Table 16.

Table 16 presents the $4.7 \%$ error of calibration coefficient in static load testing and standard bumping testing, which verifies the precision and feasibility of standard bumping testing.

\section{Conclusions}

A new method of standard bumping testing was proposed to assess the load-carrying capacity of bridges based on impact coefficient. First, vehicle speed that is less than $10 \mathrm{~m} / \mathrm{s}$ had no significant effect on impact coefficient, and deck roughness had a slight influence on impact coefficient with reasonable vehicle speeds and bumping heights; moreover, fundamental frequency, which has close relationship with stiffness and form of bridges, did have a significant effect on impact coefficient in standard bumping testing. Second, impact coefficient fitting formulas, or the relationship between impact coefficient and fundamental frequency, were established for simply supported bridges of different section forms, bumping heights, and fundamental frequency by numerical simulation. Third, impact coefficients produced by double vehicles were only marginally greater than those produced by single vehicles, with error of less than $5 \%$, which implies that midspan impact coefficient formulas developed for single vehicles could also be applied to double vehicles. 


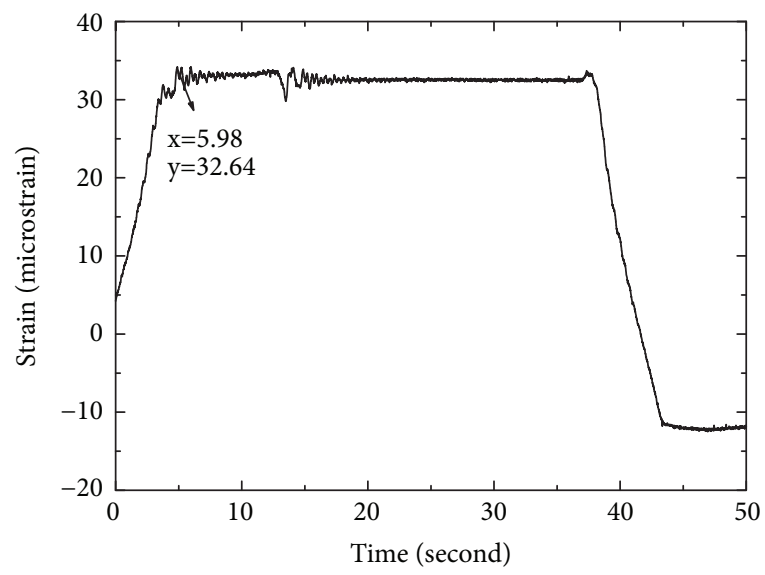

(a)

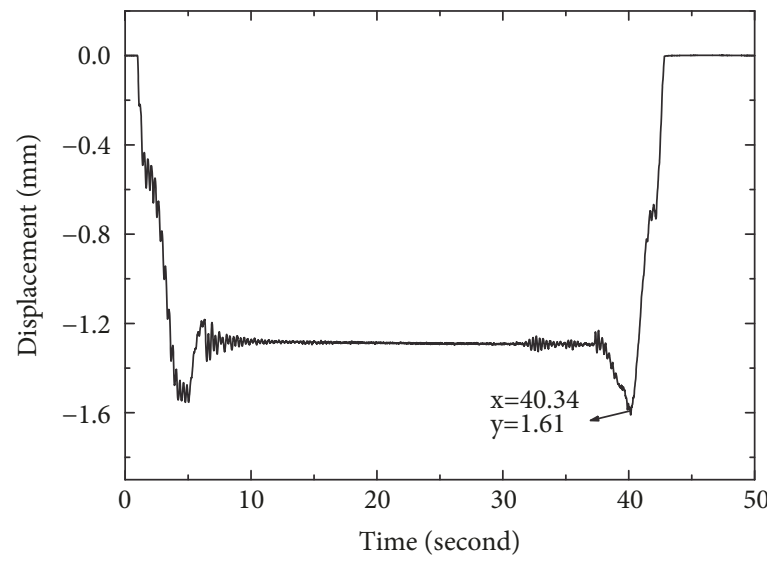

(b)

Figure 16: (a) Tensile strain in the midspan of the test bridge in static loading testing. (b) Displacement in the midspan of the test bridge in static loading testing.

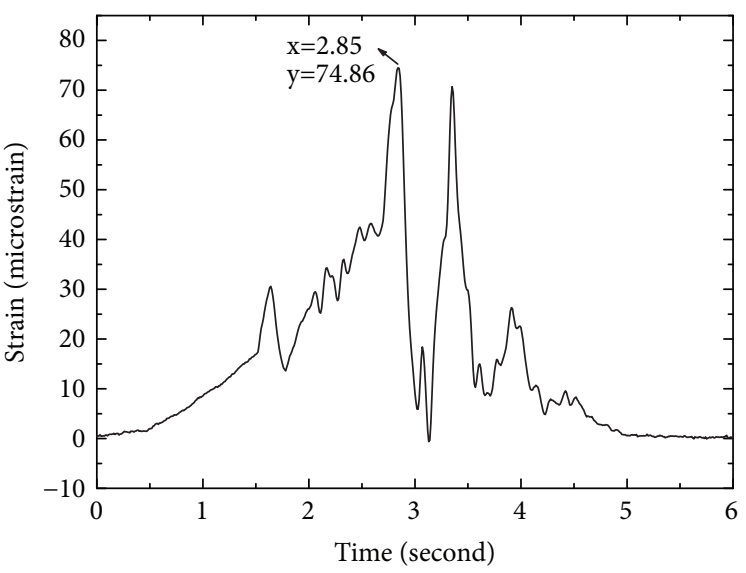

(a)

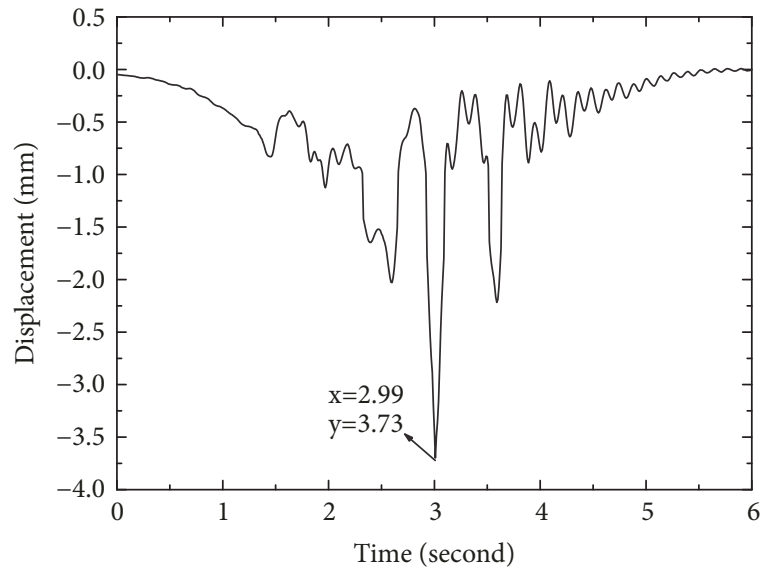

(b)

FIgURE 17: (a) Tensile strain in the midspan of the test bridge in standard bumping testing. (b) Displacement in the midspan of the test bridge in standard bumping testing.

Finally, the accuracy of impact coefficient formulas was verified through laboratory and field tests, and the precision and feasibility of standard bumping testing were validated through field testing, which offers a new method for the load-carrying capacity assessment of bridges by calibration coefficient.

\section{Data Availability}

(1) The data of figure used to support the findings of this study are included in the supplementary materials. (2) The data of table used to support the findings of this study are included within the article.

\section{Conflicts of Interest}

No potential conflicts of interest were reported by the authors.

\section{Acknowledgments}

The authors would like to acknowledge the Communication Commission of Hebei Province of China (2012033) and National Natural Science Foundation of China (51178456) for providing the funding that made this study possible.

\section{Supplementary Materials}

1. The data of figure used to support the findings of this study are included within the attachment. 2. The data of table used to support the findings of this study are included within the article. (Supplementary Materials)

\section{References}

[1] L. Frýba and M. Pirner, "Load tests and modal analysis of bridges," Engineering Structures, vol. 23, no. 1, pp. 102-109, 2001. 
[2] A. J. Cardini and J. T. DeWolf, "Long-term structural health monitoring of a multi-girder steel composite bridge using strain data," Structural Health and Monitoring, vol. 8, no. 1, pp. 47-58, 2009.

[3] L. Wang, P. Jiang, Y. Ma, and Y. Zhao, "Verification coefficient and optimization method for bridge evaluation," Journal of Highway \& Transportation Research \& Development, vol. 10, no. 2, pp. 40-46, 2016.

[4] Y. Liu and Z. Qian, "Dynamic analysis of pavement on long span steel bridge decks," Journal of Southeast University(English Edition), vol. 24, no. 2, pp. 212-215, 2008.

[5] B. Ozden Caglayan, K. Ozakgul, and O. Tezer, "Assessment of a concrete arch bridge using static and dynamic load tests," Structural Engineering and Mechanics, vol. 41, no. 1, pp. 83-94, 2012.

[6] A. P. Adewuyi, Z. Wu, and N. H. M. Kammrujaman Serker, "Assessment of vibration-based damage identification methods using displacement and distributed strain measurements," Structural Health and Monitoring, vol. 8, no. 6, pp. 443-461, 2009.

[7] F. N. Catbas, H. B. Gokce, and M. Gul, "Nonparametric analysis of structural health monitoring data for identification and localization of changes: Concept, lab, and real-life studies," Structural Health and Monitoring, vol. 11, no. 5, pp. 613-626, 2012.

[8] A. González, E. J. Obrien, D. Cantero, L. I. Ying-yan, J. Dowling, and A. Znidaric, "Critical speed for the dynamics of truck events on bridges with a smooth road surface," Journal of Sound \& Vibration, vol. 329, no. 11, pp. 2127-2146, 2010.

[9] X. He, X. Yang, and L. Zhao, "New Method for High-Speed Railway Bridge Dynamic Deflection Measurement," Journal of Bridge Engineering, vol. 19, no. 7, p. 05014004, 2014.

[10] M. Podworna and M. Klasztorny, "Vertical vibrations of composite bridge/track structure/high-speed train systems. Part 3: Deterministic and random vibrations of exemplary system," Bulletin of the Polish Academy of Sciences-Technical Sciences, vol. 62, no. 2, pp. 305-320, 2014.

[11] Y. S. Park, D. K. Shin, and T. J. Chung, "Influence of road surface roughness on dynamic impact factor of bridge by full-scale dynamic testing," Canadian Journal of Civil Engineering, vol. 32, no. 5, pp. 825-829, 2005.

[12] L. Ding, H. Hao, and X. Zhu, "Evaluation of dynamic vehicle axle loads on bridges with different surface conditions," Journal of Sound and Vibration, vol. 323, no. 3-5, pp. 826-848, 2009.

[13] B. Liu, Y.-Z. Wang, P. Hu, and Q. Yuan, "Impact coefficient and reliability of mid-span continuous beam bridge under action of extra heavy vehicle with low speed," Journal of Central South University, vol. 22, no. 4, pp. 1510-1520, 2015.

[14] P. Jiang, S. He, and Y. Song, "Coupled vibration of vehicle-bridge with local depression of continuous beam," Journal of Wuhan University of Technology, vol. 33, no. 2, pp. 82-86, 2011.

[15] X.-Y. Huang, W.-D. Zhuo, and P. Shang-Guan, "Parameter correlation study of impact factors on concrete curved box girder bridges," Advanced Materials Research, vol. 255-260, pp. 926-930, 2011.

[16] C.-W. Kim, M. Kawatani, and Y.-R. Kwon, "Impact coefficient of reinforced concrete slab on a steel girder bridge," Engineering Structures, vol. 29, no. 4, pp. 576-590, 2007.

[17] C. X. Qi, Y. H. Gao, and Q. Z. An, "Research on the effect of width-span ratio on the bridge impact coefficient," Applied Mechanics and Materials, vol. 405-408, pp. 1670-1673, 2013.
[18] L.-B. Wang and P.-W. Jiang, "1899. Research on the computational method of vibration impact coefficient for the longspan bridge and its application in engineering," Journal of Vibroengineering, vol. 18, no. 1, pp. 394-407, 2016.

[19] G. Hearn and R. B. Testa, "Modal analysis for damage detection in structures," Journal of Structural Engineering, vol. 117, no. 10, pp. 3042-3063, 1991.

[20] Research Institute of Highway Ministry of Transport, Specification for Inspection and Evaluation of Load-Bearing Capacity of Highway Bridges (JTG/T J21-2011), China Communications Press, Beijing, China, 2011.

[21] N. Jalili and E. Esmailzadeh, "Dynamic interaction of vehicles moving on uniform bridges," Proceedings of the Institution of Mechanical Engineers, Part K: Journal of Multi-body Dynamics, vol. 216, no. 4, pp. 343-350, 2002.

[22] "International Organization for Standardization ISO 8608 (1995). Mechanical Vibration-Road Surface Profiles-Reporting of Measured Data, Switzerland".

[23] X. Deng, Road sub-grade and pavement engineering, China Communications Press, Beijing, China, 2010. 


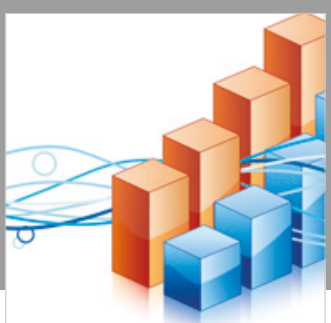

Advances in

Operations Research

\section{-n-m}
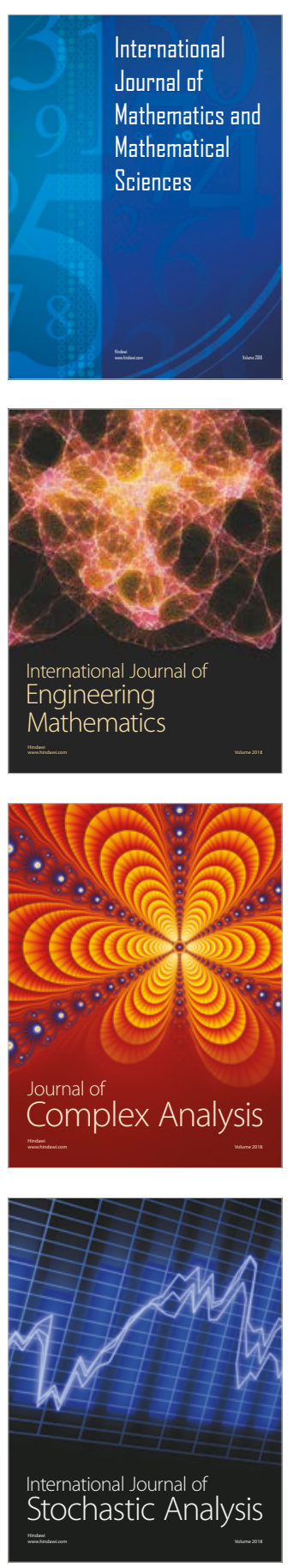
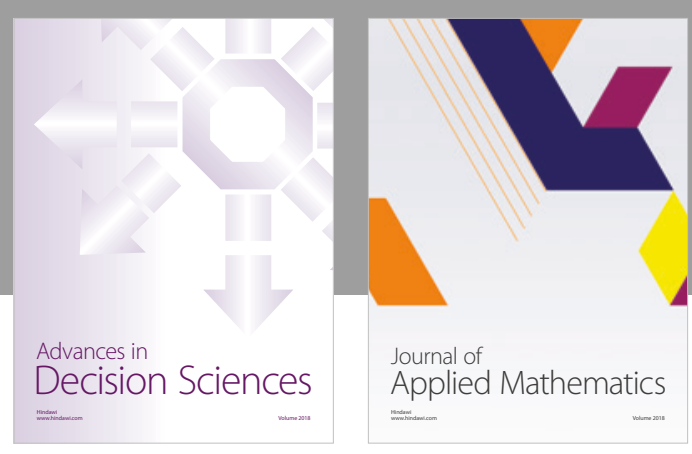

Journal of

Applied Mathematics
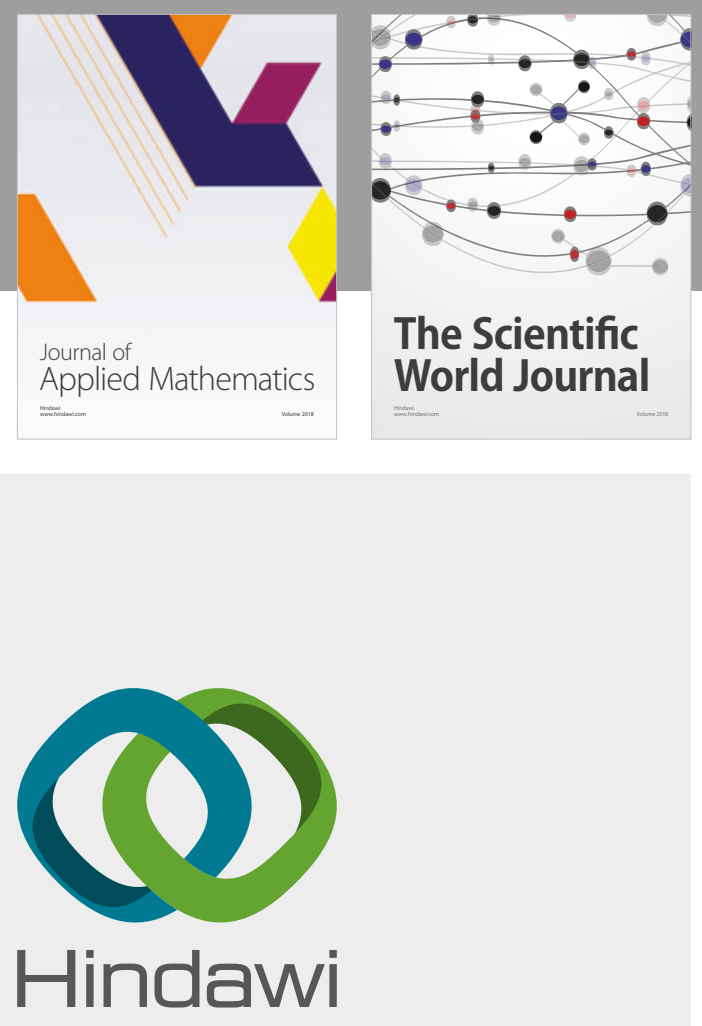

Submit your manuscripts at

www.hindawi.com

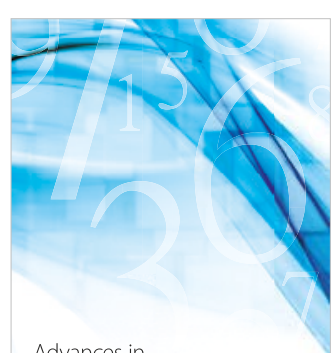

Advances in
Numerical Analysis
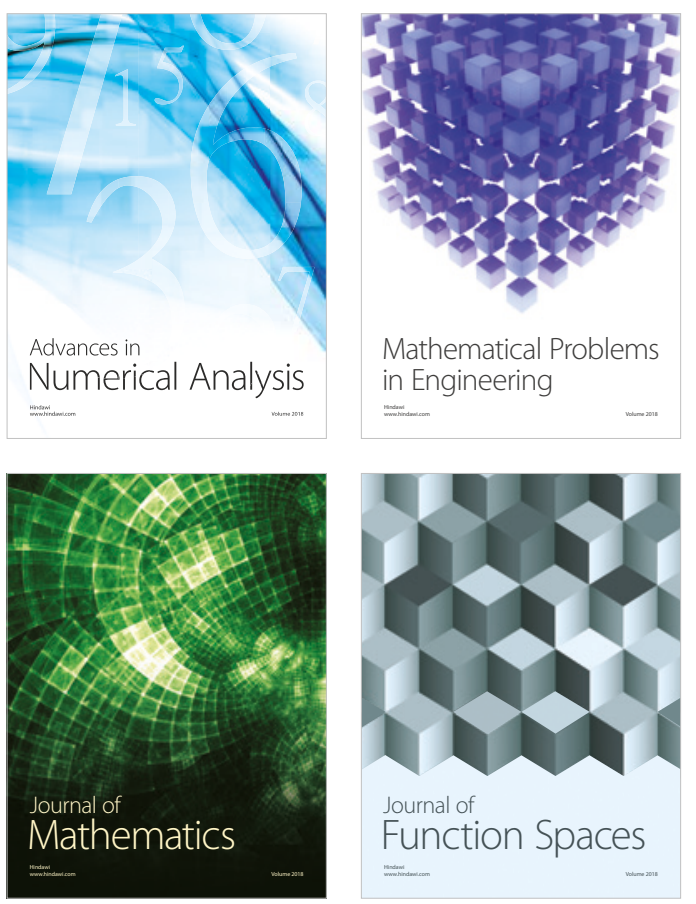

Mathematical Problems in Engineering

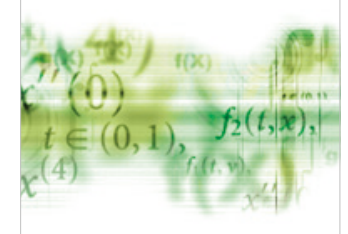

International Journal of

Differential Equations

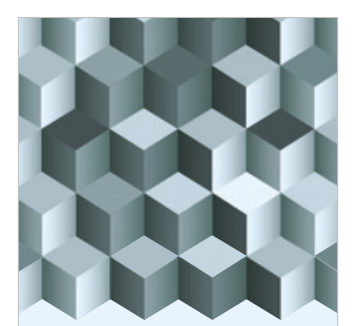

Journal of

Function Spaces
The Scientific

World Journal

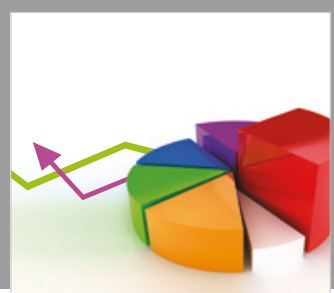

Journal of

Probability and Statistics
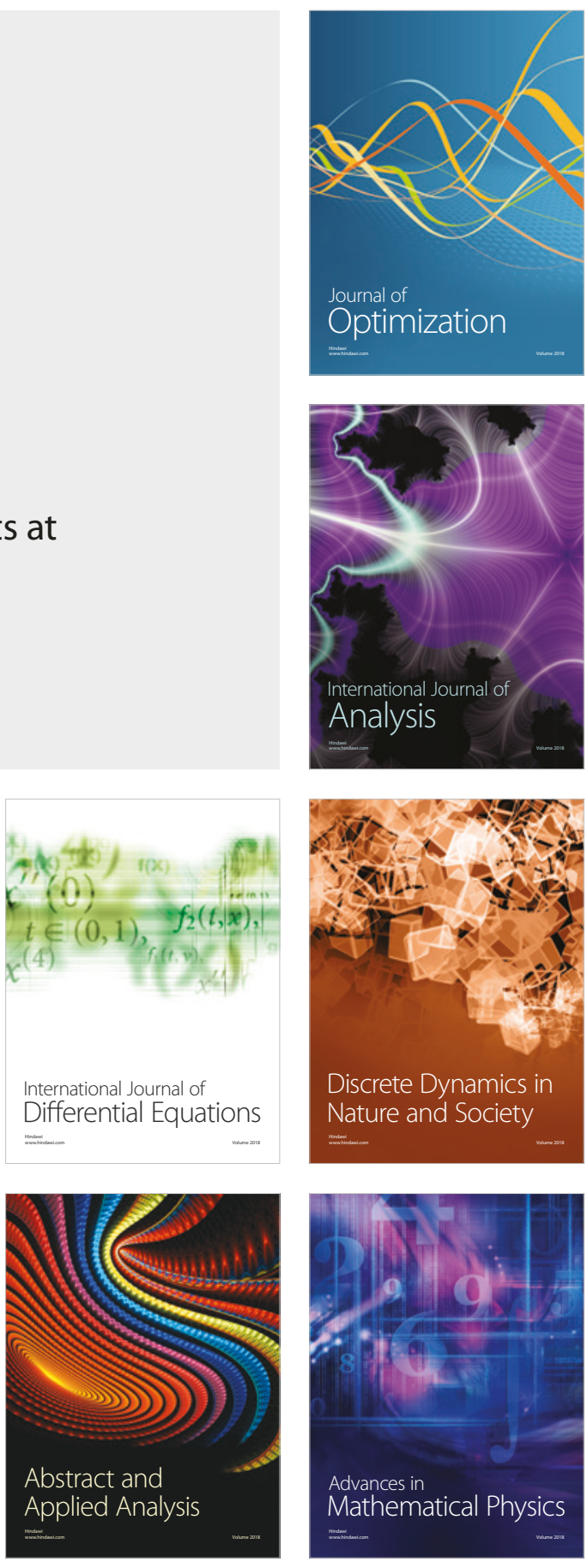